\title{
Beyond Reading the Text: Teaching Science Students Three Strategies for Mastering Complex Content
}

\author{
Gail S. Cahill \\ Barbara Govendo \\ Lesley University \\ 29 Everett Street \\ Cambridge, Massachusetts 02138 \\ USA
}

\begin{abstract}
Students today are expected to read and master information from complex text in specific academic domains, such as science. Many students are ill prepared, however, to learn and study from informational text, and most content-specific teachers, although prepared to teach the content of their respective disciplines, are often not comfortable with using explicit strategies to aid student mastery. Once again, strategy instruction is being examined, and current publications have highlighted its positive effects on student learning. This paper links the teaching of science content, using active learning strategies, to a research-based, three-pronged, effective instructional framework: the teaching of specific text features and structures; the use of content enhancements; and the teaching of cognitive strategies.
\end{abstract}

Key words: education, teacher education, teaching and learning, reading comprehension

\section{Introduction}

Currently, Common Core State Standards (CCSS) and/or individual state standards require students to understand increasingly complex informational text in science courses as they progress through the grades (U.S. Department of Education, 2010). For example, the CCSS reflect "the need for college and career-ready students to be proficient in reading complex informational text independently in a variety of content areas" (U.S. Department of Education, 2010, p. 4). Many students, however, find informational text highly intimidating (Guthrie \& Klauda, 2012), and most have never been taught how to effectively learn and study from nonfiction writing (Entress \& Wagner, 2014). Science requires extensive work to ensure that information is mastered and preserved in students' long-term memory so they can retrieve the information for the higher-level thinking required for career and college readiness as well as for STEM careers (Entress \& Wagner, 2014). Educators must, therefore, explicitly teach strategies for mastering and applying the essential ideas of the scientific disciplines, which are outlined in the Next Generation Science Standards (NGSS Lead States, 2013).

Strategy instruction was highly researched three decades ago, and there has been a shift in focus back to this practice (Vann Keer \& Verhaeghe, 2005). Recent studies highlight the positive effects of direct instruction on the deeper, or close, reading of informational texts (Cahill \& Govendo, 2014; Jitendra \& Gajria, 2011; Wanzek et al., 2020). Students must more fully engage with text to develop greater mastery, whether they are learning how to balance a chemical equation or analyze experimental data.

Teaching science content requires students to read informational text from various sources, such as textbooks and articles. Students often initially read to gain an overall understanding of the material. Then, the following readings of the same text might focus on vocabulary and digging deeper into the content, using guided questions, making inferences, documenting opinions, or making connections to another text (Lapp et al., 2013). We often hear from science teachers that students connect text features and structures to literary text but do not often make the connection to science texts. A goal for science educators, therefore, is to ensure that students make these connections.

Research that explores how students learn best has the potential to bolster science instruction as we work to help students move toward higher levels of thinking. Medina (2008) found that students' attention wanes after about 15 minutes of a lecture. Bonwell and Eison (1991) coined the term "active learning" for activities that stimulate learning and the retention of learned information as well as augment academic achievement. A recent study found, however, that students need to be shown that they learn more through active learning activities than through lecture (Deslauriers et al., 2019). 
Active learning has also been associated with stimulating creative thinking by promoting individual and group ideas (Gargiulo \& Metcalf, 2017; Park \& Choi, 2014), which is the type of thinking needed in STEM careers. Strategy instruction coupled with active learning in classrooms holds great promise for ensuring that students are career and college ready and prepared for STEM futures.

What follows is a description of three research-based intervention strategies that science educators and students can learn and apply to informational text reading. These strategies enhance knowledge and mastery of science content as students move beyond just reading the text to gaining a deeper understanding of the text. These strategies are clustered into three areas: text features and structures; content enhancements; and cognitive strategies. A description of each strategy is followed by classroom ideas that promote active learning.

\section{Strategy One: Teach Text Features and Structures}

Informational texts have many common features, including headings or subtitles, tables of contents, pictures and captions, diagrams, cross-sections, glossaries, and inset photos (Cahill \& Govendo, 2014; Kelley \& Clausen-Grace, 2010). Informational text structures are divided into two categories: descriptive texts and string-patterned texts, or texts that are affected by time (Dymock, 2005). Research has shown that explicit teaching of text features and structures positively influences the reading comprehension of students (Dymock \& Nicholson, 2010; Hall et al., 2005; Pearson \& Duke, 2002; Sweet \& Snow, 2003; Wanzek et al., 2020). In essence, text features are visual supports that help students to delve deeper into complex text with greater understanding; and, as Shanahan et al. (2012) have documented, students who understand text features and structures have an advantage in making sense of expository text. This sense-making enables students to gain a greater comprehension of the text that then allows teachers to spend more time creating activities and projects that "go deeper" and support higher-level thinking skills.

\section{Classroom Ideas}

Science educators can use a variety of activities to support students' understanding of complex informational text, with and without the use of digital technologies. Text features, such as tables of contents, headings, pictures, captions, charts, and graphs, are incorporated into informational texts. One useful strategy is text feature preview. This activity asks students to skim headings and look at diagrams and pictures to make predictions about the chapter or article before they read. One idea is to compile the information from skimming text features into an oral or written prediction of the text that can be referenced periodically during the unit of study. The importance of understanding text features is to build background knowledge of and connectivity to the text prior to reading and can function as a pre-assessment. As Shanahan et al., (2012) have documented, students who understand text features and structures have an advantage in making sense of expository text. These pre-reading actions are critical for students because they provide them with the necessary foundation to be successful with higher order thinking activities.

\section{Classroom Activity: All About ...}

Classrooms at all grade levels can create "All About . . ." projects that incorporate text features and structures. For example, in one high school classroom, we watched as students worked in pairs to develop PowerPoint presentations that served as an overview of a unit on molecules. At another high school, students used Google Docs to create a similar "All About ..." project that incorporated the use of current reference articles related to food chains. Both presentations, of molecules and food chains, included section headings, charts, and graphs linked to the overall comprehension of the related text. The tasks also demonstrated student independence in using these features to help their peers to understand scientific content. In the latter classroom, the teacher created a checklist with the students to assess the incorporation of text features and structures in their presentations. The title of the checklist was, "Did we ... ?"and included questions such as, "Did we include all the section headings?"; "Did we include graphs?"; and, "Did we include a glossary?"

\section{Strategy Two: Teach Content Enhancements}

Teachers use content enhancements to help students to organize, understand, and learn information. These strategies are used to keep students actively engaged with the curriculum, which benefits all students (Deshler et al., 1996; Gargiulo \& Metcalf, 2017). The teacher identifies the most important content for the students to learn and then uses active learning strategies to teach the information in smaller, easy-to-understand segments of information or uses visual structures that help students to understand vocabulary and larger concepts. 


\section{Classroom ideas}

Informational texts in science classes are moving beyond the typical textbooks to include multimedia content, and teachers are discovering many ways to enhance the essential ideas outlined in the Next Generation Science Standards (NGSS Lead States, 2013). It is important to remember that content enhancements are teacher driven; that is, enhancements are active strategies that teachers use to help students understand academic content. For example, students in a high school class might read a research article based on specific science content and then watch a video on YouTube that animates the content. Other content enhancement ideas include study guides, mnemonic devices, and pairing key vocabulary and/or concepts with visual representations either downloaded from the Internet or drawn by students.

\section{Classroom Activity: Concept Anchoring Table}

Concept anchoring is a higher order thinking strategy that connects previously learned concepts to new concepts(Deshler et al., 1996).Most often, we have observed this strategy with graphic organizers, either linear with columns or a Venn diagram, whereby characteristics of the already known concept are listed in the left column/circle, characteristics of the new concept are listed in the right column/circle, and the shared characteristics are listed in the middle column/circle. One interesting spinoff is the use of a free website, padlet (padlet.com).

In a tenth-grade science classroom that we observed, a teacher explained how he often uses a padlet to generate ideas, hold discussions, and play games. He also downloads the completed padlet as a pdf so that students can use it as a study guide. Figure 1 illustrates a padlet organized as a concept anchoring table.

Figure 1Sample padlet of concept anchoring (padlet.com)

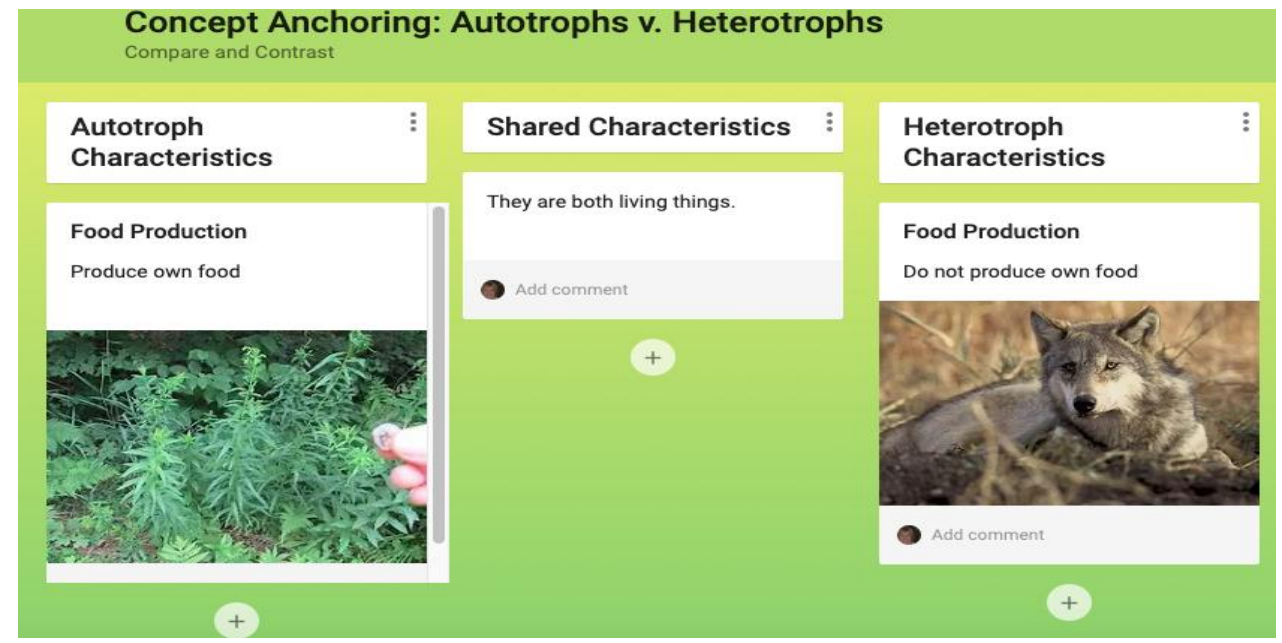

\section{Strategy Three: Teach Cognitive Strategies}

Cognitive strategies focus on the "how" of learning. These strategies include predicting, visualizing, and paraphrasing. These tools are designed to be used when students are learning content, whether listening, reading independently, or learning through videos (Deshler et al., 1996). These strategies also have been successfully used with students with disabilities. For example, Gajria et al., (2007) found that systematic instruction in cognitive strategies enhanced text comprehension for students with specific learning disabilities. It is increasingly important that students learn how to discern and critically evaluate scientific information from various sources for career and college readiness.

\section{Classroom Ideas}

There are many cognitive strategies that teachers can use to guide students in understanding "how" to understand complex text and monitor their work. We often design self-monitoring checklists with students to help them to assess their success, using varied learning strategies (e.g., I used strategy to help me study for the exam. Result.

Reflection on result; I prepared for my oral presentation by . Result. Reflection on result). 
One classroom idea to support students' self-guided understanding of complex texts is to teach question-answer relationships. Raphael and Au (2005) describe different types of questions generally asked of students. It is helpful for students to understand that they can find the answers to "Right There" questions in one section of the text, while the answers to "Think and Search" questions may be in different sections of the text, for which students will need to analyze, summarize, and synthesize information to discover the main idea, ask questions, or make a prediction.

\section{Classroom Activity: Quizlet}

We watched a science educator model "Right There" and "Think and Search" questions (Conley, 2012; Raphael \& Au, 2005). The teacher posed questions and asked the students to help her to determine whether she could find the answers directly in the text ("Right There") or whether the answers required her to pull together information from the text ("Think and Search").Upon completion, she assigned students to four groups. As a formative assessment, each group had to complete five "Right There" questions and answers and three "Think and Search" questions and answers based on text that focused primarily on several specific curriculum standards that they had studied. The questions were reviewed by students and compiled into a classroom quizlet (quizlet.com) that was then used as part of their study guide for the upcoming summative unit assessment (Figure 2).

Figure 2Sample quizlet.com self-questioning study guide

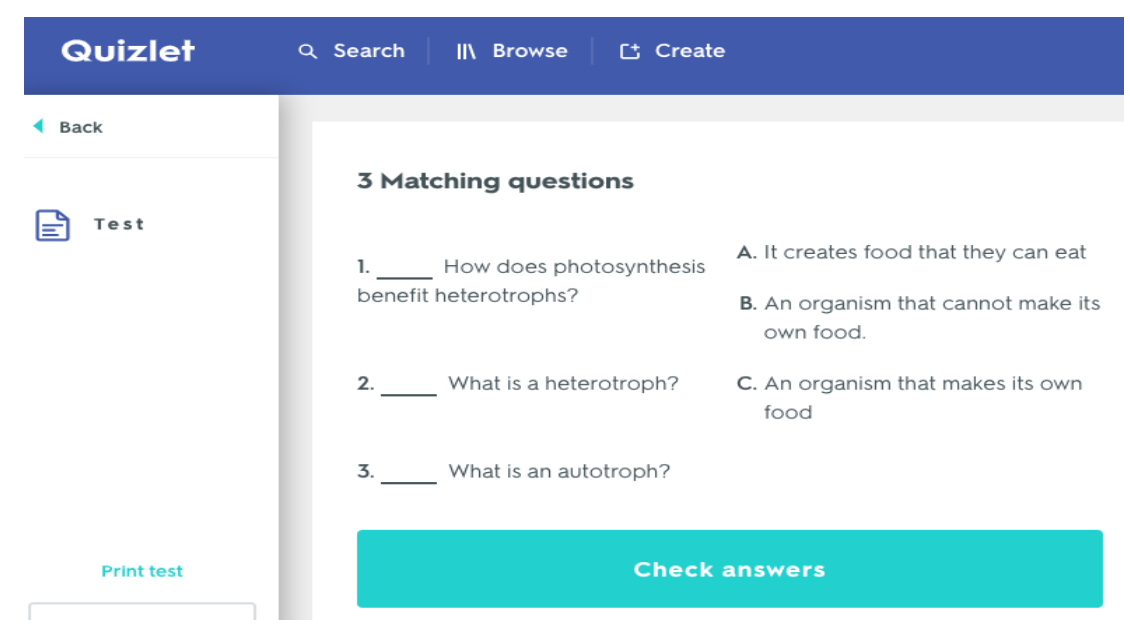

\section{Conclusion}

Students are expected to read and understand complex science text, and educators are expected to teach it well. Given rigorous standards and often diminished instructional time, educators need an efficient framework. This paper presented three research-based intervention areas, with accompanying strategies, to aid in the comprehension of science texts: text features and structures; content enhancements; and cognitive strategies. These three intervention areas and active learning strategies will support science educators as they move students beyond reading the text to mastering complex content that is addressed in the Next Generation Science Standards and are needed to prepare students for careers and college to include STEM specializations.

\section{References}

Bonwell, C. \& Eison, J. (1991) Active learning: Creating excitement in the classroom. Jossey-Bass.

Cahill, G., \& Govendo, B. (2014). A good reader has a plan: Helping students with learning disabilities. Learning Disabilities: A Multidisciplinary Journal, 20(3), 158-163.

Conley, M. (2012). Content area literacy (2nd ed.). Pearson.

Deshler, D. D., Ellis, E. S., \& Lenz, B. K. (1996). Teaching adolescents with learning disabilities (2nd ed.). Love.

Deslauriers, L., McCarty, L. S., Miller, K., Callaghan, K., \& Kestin, G. (2019). Measuring actual learning versus feeling of learning in response to being actively engaged in the classroom. Proceedings of the National AcademyofSciencesoftheUnitedStatesofAmerica,116(39),1925119257.https://doi.org/10.1073/pnas.1821936116

Dymock, S. (2005). Teaching expository text structure awareness. The Reading Teacher, 59(2), 177-181. 
Dymock, S. J., \& Nicholson, T. (2010). "High 5!" Strategies to enhance comprehension of expository text. The Reading Teacher, 64(3), 166-178.

Entress, C., \& Wagner, A. (2014). Beyond "hitting the books": Teaching science students strategies for studying independently, The Science Teacher, 81(4), 27-31.

Gajria, M., Jitendra, A., Sood, S., \& Sacks, G. (2007). Improving comprehension of expository text in students with LD: A research synthesis. Journal of Learning Disabilities, 40(3), 210-225.

Gargiulo, R. M., \& Metcalf, D. (2017). Teaching in today's inclusive classrooms: A universal design for learning approach. Cengage Learning.

Guthrie, J., \& Klauda, S. (2012). Making textbook reading meaningful. Educational Leadership, 69(6), 64-68.

Hall, K., Sabey, B., \& McClellan, M. (2005). Expository text comprehension: Helping primary-grade teachers use expository texts to full advantage. Reading Psychology, 26, 211-234.

Jitendra, A. K., Hoppes, M. K., \& Xin, Y. P. (2000). Enhancing main idea comprehension for students with learning problems: The role of a summarization strategy and self-monitoring instruction. The Journal of Special Education, 34(3), 127-139.

Kelley, M., \& Clausen-Grace, N. (2010). Guiding students through expository text with text feature walks. The Reading Teacher, 64(3), 191-195.

Lapp, D., Grant, M., Moss, B., \& Johnson, K. (2013). Students' close reading of science texts. The Reading Teacher, 67(2), 109-119.

Medina, J. (2008). Brain rules: 12 principles for surviving and thriving at work, home and school. Pear Press.

NGSS Lead States. (2013). Next generation Science standards: For states, by states. National Academics Press.

Park, E. L. \& Choi, B. K. (2014). Transformation of classroom spaces: Traditional versus active learning classroom in colleges. Higher Education, 68, 749-771. https:/doi.org/10.1007/s10734-014-9742-0

Pearson, P. D., \& Duke, N. (2002). Comprehension instruction in the primary grades. In C. C. Block \& M. Pressley (Eds.), Comprehension instruction: Research-based practices (pp. 247-258). Guilford Press.

Raphael, T., \& Au, K. (2005). QAR: Enhancing comprehension and test taking across grades and content areas. The Reading Teacher, 59(3), 206-221.

Shanahan, T., Fisher, D., \& Frey, N. (2012). The challenge of challenging text. Educational Leadership, 69(6), 58-62.

Sweet, A. P., \& Snow, C. E. (Eds.). (2003). Rethinking reading comprehension. Guilford Press.

U. S. Department of Education. (2010). National Assessment of Educational Progress (NAEP), 1992-2009 Reading Assessments. Washington, DC: Institute of Education Sciences, National Center for Education Statistics.

Van Keer, H., \& Verhaeghe, J. P. (2005). Effects of explicit reading strategies instruction and peer tutoring on second and fifth graders' reading comprehension and self-efficacy perceptions. The Journal of Experimental Education, 73(4), 291-329.

Wanzek, J., Al Otaiba, S., \& McMaster, K. L. (2020). Intensive reading interventions for the elementary grades. Guilford Press. 